\title{
Limb Salvage - at Which Costs, Which Risks?
}

\section{T. Schneiter T. Hunziker}

Department of Dermatology, University of Bern, Bern, Switzerland

According to the EMEA, the European Agency for the Evaluation of Medicinal Products, and Swissmedic, the Swiss Agency for Therapeutic Products, all tissue engineering products using cultured cells should now be regulated by requirements close to those used for drugs (EU guideline 1394/2007 for 'advanced cellular therapeutics'). Such inappropriate hurdles risk to paralyze the entire field of treating recalcitrant skin wounds using cultured but otherwise not manipulated autologous keratinocytes [1].

To prevent this, we report the case of a 64-year-old female suffering from a refractory pretibial leg ulcer in the course of systemic scleroderma. After surgery and vacuum-assisted closure therapy, which both failed, we treated the patient with EpiDex, an epidermal equivalent organotypically cultured from autologous outer root sheath keratinocytes of plucked anagen scalp hair follicles $[2,3]$. On an outpatient basis, the leg ulcer was reepithelialized within 6 months (fig. 1).

Presently, EpiDex is reimbursed in Switzerland for recalcitrant vascular leg ulcers $(\mathrm{CHF} 4,800$ for $3 \times 6$ 1 -cm disks) as an alternative to inpatient surgical procedures, which are at least as costly. Spectacular cases as the one presented should help to keep this noninvasive transplantation technology available for carefully selected difficult-to-treat wounds. The outer root sheath contains pluripotent adult stem cells [4]. Organotypically cultured

\section{KARGER}

Fax +4161306 1234 E-Mail karger@karger.ch www.karger.com
(C) 2010 S. Karger AG, Basel

$1018-8665 / 11 / 2221-0020 \$ 38.00 / 0$

Accessible online at:

www.karger.com/drm

outer root sheath keratinocytes, however, keep perfect tissue homeostasis [5], and tumors arising in an EpiDextreated area have never been reported so far. Thus, instead of 'overregulating', regulatory authorities should fine-tune their requirements, carefully weighting potential benefits for the patients versus costs and risks of the individual tissue engineering technology at stake.

References

T. Schneiter

Department of Dermatology

University of Bern, Hochschulstrasse 4

CH-3012 Bern (Switzerland)

E-Mail thomas.schneiter@insel.ch 

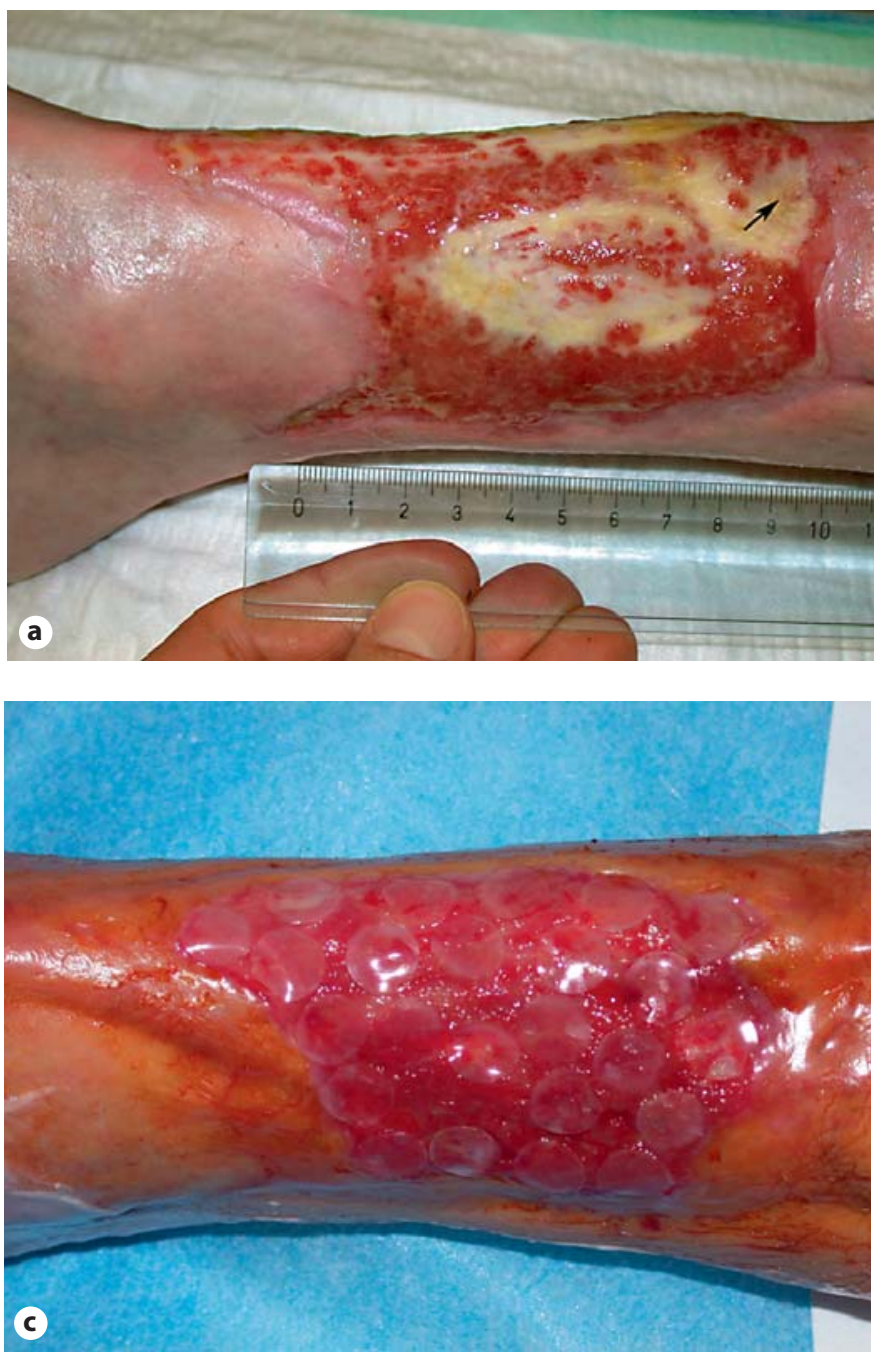

Fig. 1. a Pretibial leg ulcer before the first EpiDex application. Despite vacuum-assisted closure therapy for 4 weeks, the $100-\mathrm{cm}^{2}$ wound is granulating partially only, fascia and tendons are exposed, probe-to-bone in the proximal edge is positive (arrow). b First EpiDex application: 18 EpiDex disks of $1 \mathrm{~cm}$ in diameter are applied to the granulating wound areas mainly, with some
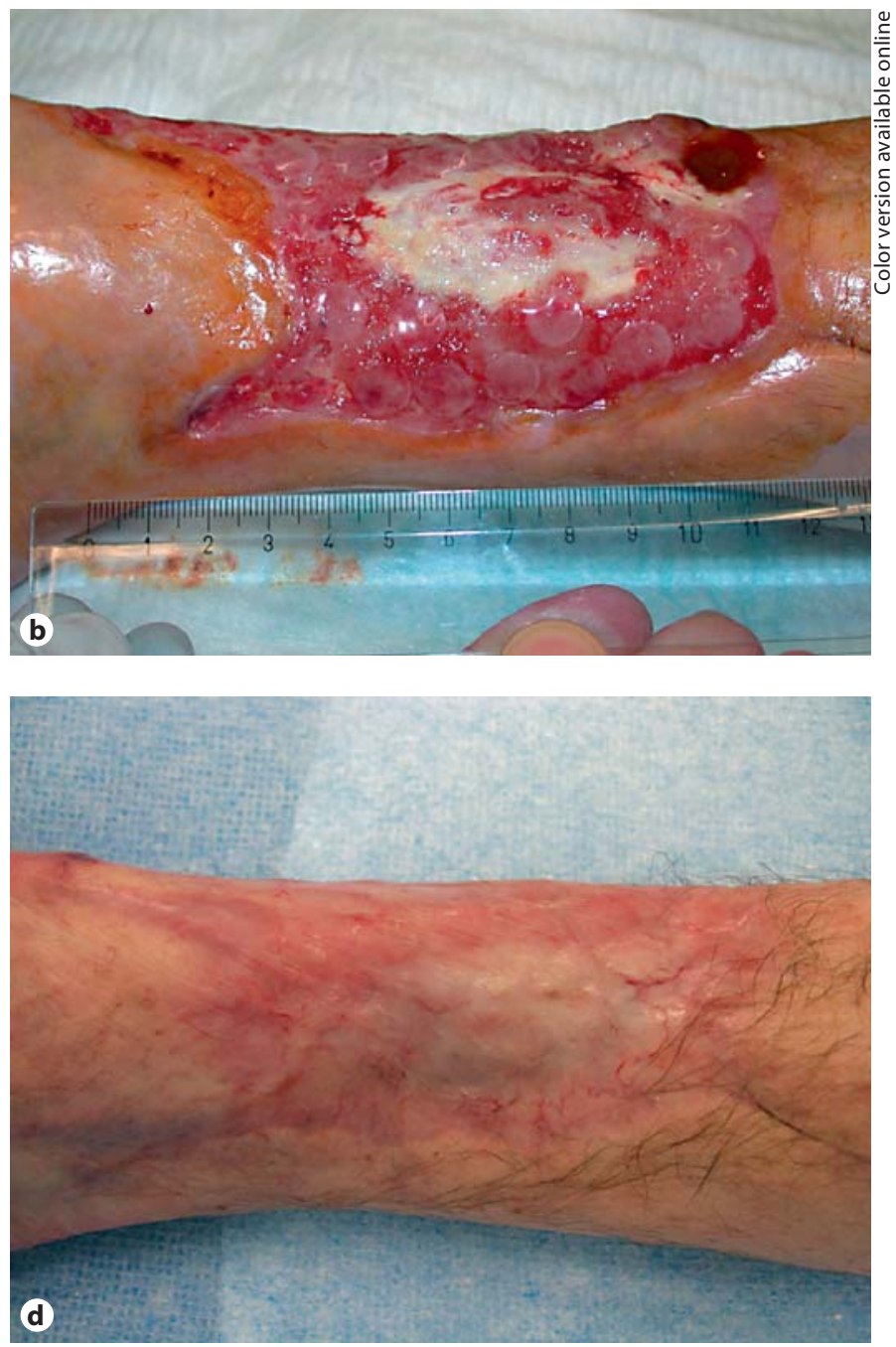

overlapping to tendons and fascia. c Second EpiDex application 8 weeks after the first: the wound area is reduced to $85 \mathrm{~cm}^{2}$, fascia and tendons are completely covered by granulation tissue, probeto-bone is negative; 24 EpiDex disks of $1 \mathrm{~cm}$ in diameter are applied in a dense manner. d 24 weeks after starting the EpiDex treatment: the wound is completely reepithelialized. 